\title{
Editorial
}

\section{einstein na PubMed}

\section{einstein is indexed in PubMed}

Luiz Vicente Rizzo

Diretor Executivo do Instituto de Ensino e Pesquisa Albert Einstein

Nos últimos trinta anos a prática médica vivenciou uma importante revolução. Moveu-se da medicina anedótica para a medicina baseada em evidência. Essa tendência ficará ainda mais importante com a inclusão de análises da economia da saúde às melhores práticas médicas. No centro desse movimento está a reunião de informações de confiança revisadas pelos pares. Apesar do processo de revisão por pares estar sob escrutínio, atualmente é o melhor método disponível de validação de dados científicos.

Em ciências da saúde, a PubMed/ MEDLINE tornou-se o padrão ouro para bases de dados com informações inquestionáveis. As decisões médicas, o gerenciamento do paciente, e a base para a pesquisa futura são em grande parte determinados pelo que é publicado nessa base. Esse reconhecimento pela comuni- dade científica da saúde foi alcançado, pelo fato de que a indexação na base de dados PubMed só é dada aos periódicos de maior qualidade na área. $\mathrm{O}$ processo rigoroso que o comitê de indexação aplica para cada periódico candidato garante tal qualidade e consequentemente a importância que é dada no que é publicado nos periódicos indexados na PubMed.

A einstein acabou de ser indexada em abril. Além do reconhecimento óbvio ao grupo de produção e gerenciamento da instituição, isso também significa comprimentos a todos os autores dos artigos publicados no periódico, já que sua qualidade foi validada no mais alto nível científico possível.

Agora, devemos cuidar para recrutar trabalhos ainda melhores, para mover nosso fator de impacto rapidamente para cima. Vamos continuar com o bom trabalho e melhorá-lo. 